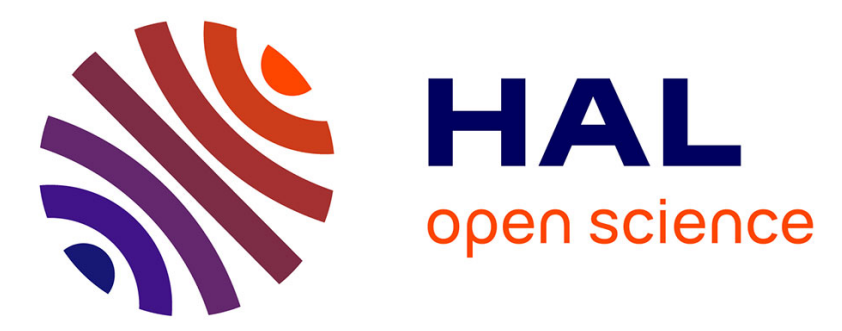

\title{
El Contra Judaeos de Isidoro de Sevilla en la predicación regular ibérica del final del siglo xii. Entre identidad confesional y estatutaria
}

Amélie De las heras

\section{- To cite this version:}

Amélie De las heras. El Contra Judaeos de Isidoro de Sevilla en la predicación regular ibérica del final del siglo xii. Entre identidad confesional y estatutaria. Christian, Jewish, and Muslim Preaching in the Mediterranean and Europe. Identities and Interfaith Encounters, 2019, 978-2-503-58271-9. 10.1484/M.SERMO-EB.5.116669 . halshs-02508156

\section{HAL Id: halshs-02508156 \\ https://shs.hal.science/halshs-02508156}

Submitted on 13 Mar 2020

HAL is a multi-disciplinary open access archive for the deposit and dissemination of scientific research documents, whether they are published or not. The documents may come from teaching and research institutions in France or abroad, or from public or private research centers.
L'archive ouverte pluridisciplinaire HAL, est destinée au dépôt et à la diffusion de documents scientifiques de niveau recherche, publiés ou non, émanant des établissements d'enseignement et de recherche français ou étrangers, des laboratoires publics ou privés. 


\section{EL CONTRA JUDAEOS DE ISIDORO DE SEVILLA EN LA PREDICACIÓN REGULAR IBÉRICA DEL FINAL DEL SIGLO XII. ENTRE IDENTIDAD CONFESIONAL Y ESTATURIA*}

¿Hasta qué punto la predicación del siglo XII es un buen indicador de las relaciones interconfesionales o transculturales en una región determinada, cuando parece abordarlas? La peculiaridad multiconfesional del ámbito mediterráneo ha conducido a menưdo a la prevalencia de este prisma interpretativo; pero cabe tenerse más en cuenta la incidencia del modelo en los sermones cristianos. Dicho problema se plantea en el estudio de esa literatura por el dominio de la autoridad y por el recurso frecuente a la compilación de un material producido en otro contexto. ${ }^{1}$ Del peso de las autoridades, además, resulta la circulación de una especie de codificación simbólica del conocimiento; basta pensar en Beda el Venerable que, de manera paradigmática, escribió sobre judíos sin conocer a ningún hebreo. ${ }^{2}$ En las prácticas de saber medievales, pesan tanto el modelo-imitación (compilación) y el modelo-tipo ideal de M. Weber (estereotipo) — ambos relacionados con la cuestión fundamental de la autoridad - que resulta difícil discernir en la redacción de un sermón la preocupación de facto por una realidad multiconfesional. ${ }^{3}$

Es aún más delicado cuando se trata de la predicación monástica o canónica del siglo XII. Aunque está dirigida en gran medida a los religiosos, enfocando asuntos inter-comunitarios (disciplina, lectio divina - lectura e interpretación de la Biblia — ...), algunos sermones no hacen caso omiso de los temas extra-comunitarios así como interconfesionales. No se conoce bien este tipo de predicación hasta el final del siglo XII; por ejemplo se sabe, por cartas y por crónicas, que Bernardo de Clairvaux predicó sobre la Cruzada, pero no se conservan los sermones. ${ }^{4}$

En esta área, los sermones de Martino de León ofrecen un caso de estudio a la vez extraordinario y significativo. Primero, es una fuente muy valiosa. Se conservan muy pocos sermones cristianos ibéricos del siglo XII, aun cuando crónicas o relatos hagiográficos señalan el mantenimiento de la actividad. ${ }^{5}$ En cambio, del canónigo regular leonés, conocemos no menos de cincuenta y cuatro sermones. Los escribió en su colegiata

* Este trabajo ha sido realizado gracias a una Pensión de la Fundación Thiers, en colaboración con el Instituto de Investigación y de Historia sobre los Textos (IRHT-CNRS), y en el marco del Proyecto de Investigación FFI2015-63659-C2-1-P financiado por el Ministerio de Economía y Competitividad. Agradezco a Cándida Ferrero por su paciente revisión de la ponencia.

\footnotetext{
${ }^{1}$ Kienzle ed., The sermon.

${ }^{2}$ Scheil, The Footsteps of Israel.

${ }^{3}$ Sobre el doble índole del modelo en la Edad Media: Sangirardi, «Le modèle».

${ }^{4}$ Kienzle ed., The Sermon, pp. 306-312.

${ }^{5}$ Martín ed., Sources latines, pp. 167-190.
} 
San Isidoro de León, de 1185 hasta su muerte en 1203; al conjunto, al que hay que añadir cuatro comentarios bíblicos, le dio el siguiente título: la Veteris ac Novi Testamenti Concordia ${ }^{6}$ Sin embargo, la Concordia no ha sido lo suficientemente estudiada, quizás por la mala fama que precedía las obras-compilaciones, hasta hace poco: según una historiografía obsoleta, no habrían sido adecuadas en cuanto a descubrimientos científicos. ${ }^{7}$

Segundo, el caso de estudio permite centrar la atención sobre la interferencia de la autoridad y del problema de la imitación ya que Martino de León, concretamente, se dedicó a una extraordinaria compilación de obras patrísticas, y también carolingias y posteriores. ${ }^{8}$ En la omnipresencia del material extranjero o antiguo, conviene destacar la influencia de Isidoro de Sevilla (m. 636), el santo patrón de la colegiata San Isidoro. El lector encuentra en particular una gran cantidad de extractos del De fide catholica, contra Judaeos, una recogida de testimonia bíblicos demostrando el error de los judíos, que Isidoro dedicó a su hermana Florentina. ${ }^{9}$ Martino la utilizó en ocho sermones $\square$ más: todavía nos falta una edición de la Concordia que revise la del siglo XVIII, publicada en la Patrologia Latina -: In Adventu Domini II (el segundo sermón en la PL), De Natale Domini ( $3^{\text {ro }}$ ), In Natale Domini II (4), In Coena Domini II (22), In Coena Domini III (23), De Resurrectione Domini III (26), In Ascensione Domini (30), In festivitate Sanctae Trinitatis (34). En algunos casos, la reutilización es masiva o incluso estructuradora.

Tercero, con el apoyo de esa fuente, entre otras, Martino desarrolló un discurso antijudaico notable, casi en la mitad de sus textos: es la característica más estudiada de la Concordia. ${ }^{10}$ Sin negar su importancia en la economía de la obra, cabe revisar las opiniones, derivadas de la tesis de Antonio Viñayo, según las que la Concordia habría principalmente sido producida como obra de controversia, incluso enfocada hacia la conversión de los judíos. ${ }^{11}$ En opinión del historiador-abad de la colegiata de San Isidoro, estas intenciones habrían respondido a una urgencia. A finales del siglo XII, una comunidad hebrea - el denominado Castro de los Judíos - era contigua a la ciudad. Su dispersión en 1196 por los ejércitos de Alfonso VIII de Castilla y de Pedro II de Aragón, unidos contra Alfonso IX de León, pudo fortalecer a algunos grupos hebreos dentro de la ciudad, crear a otros; quizás fomentara un sentimiento de encierro. Tal vez fue un tiempo de crispación interconfesional. ${ }^{12} \mathrm{Al}$ afianzarse en esa coyuntura, Antonio Viñayo propuso análisis

${ }^{6}$ Dos estudios parciales: Viñayo, Santo Martino de León e Id. ed., Santo Martino de León: ponencias.

7 Un ejemplo de devaluación: Flórez, 'El sacramento de la penitencia', p. 658: 'No es [...]el fruto de una reflexión personal o de una propia elaboración'. Se considera más ahora eso tipo de obras, por lo que reflejan las redes y las prácticas de saber; en el ámbito francés, por ejemplo: Toubert y Moret ed., Remploi, citation, plagiat; Zimmermann ed., Auctor et auctoritas.

${ }^{8}$ De Las Heras, 'Martin de León (m. 1203)'; Robles, 'Fuentes'; Viñayo, 'San Martín de León, el primer'.

${ }^{9}$ Una edición reciente del primero libro del Contra Judaeos existe pero J. Elfassi estima que, al carecer de un stemma y de aparatos suficientes, es 'apenas crítica': Elfassi, 'Les Psaumes', p. 168. Por eso, se sirve aquí de la edición publicada en la $P L$, más cómoda.

${ }^{10}$ Fundamental: Viñayo, San Martín de León y su apologética.

${ }^{11}$ Varios estudios plantean la finalidad de la conversión hebraica o, al menos, la reacción directamente polémica frente al auge de la presencia judaica: Viñayo, San Martín de León y su apologética, pp. 63-64, 105, etc.; Niclós, 'San Martín de León y la controversia', pp. 251-252; Rucquoi, 'L'invective', p. 137: 'la Concordia est en effet un long traité apologétique qui pourrait porter le titre d'Adversus Iudaeos'.

${ }^{12}$ Rodríguez, 'Los judíos'. 
literales de los sermones, alegando que Martino los destinaron a luchar contra los judíos leoneses o sus rabinos, como Pedro Alfonso (m. c. 1140) dos generaciones antes. ${ }^{13}$ Arsenio Frugoni y varios otros autores demostraron ulteriormente el peligro de tal método de combinación. ${ }^{14}$ Sin embargo, la alegación pronto tuvo seguidores que se centraron asimismo en el estudio del cuarto sermón, como lo hizo en gran medida Antonio Viñayo. ${ }^{15}$ La Concordia no se resume a dicho texto aunque represente una cuarta parte de la totalidad; y veremos que el Sermo in Natale Domini II no es un texto con finalidad de predicación. A nuestro parecer, además, los estudios no tomaron suficientemente en cuenta a los receptores, es decir a los canónigos regulares de San Isidoro. Bien se conoce la vocación hospitalaria de la comunidad; en cambio, sus actividades pastorales vinculadas a la cura animarum son muy presumiblemente poco numerosas. ${ }^{16} \mathrm{La}$ posibilidad de que Martino de León hubiera escrito para canónigos que se dirigieran ellos mismos a los fieles o a los judíos, es por lo tanto baja.

A los problemas de metodología se añadieron varias confusiones historiográficas. La demostración se arraigó a menudo en el uso notable del Contra Judaeos de Isidoro de Sevilla, considerado hasta hace poco como obra de controversia directa; y su uso, como un rasgo claro del afán de conversión judía. ${ }^{17} \mathrm{Al}$ contrario de lo que suponía Antonio Viñayo, Wolfram Drews argumentó de modo convincente que el obispo de Sevilla no redactó su tratado con motivos contextuales tales como la política antijudaica de Sisebut, no lo dirigió a los Hebreos para convertirlos, sino a los católicos para fortalecerles en su fe: el trabajo adopta la forma de la controversia con fines pedagógicas. ${ }^{18}$ Sin prejuzgar del uso del Contra Judaeos que haga Martín de León, la revisión de W. Drews invita a revisar los análisis precedentes. Además, el uso del Contra Judaeos no es habitual en la literatura del siglo XII o anterior, al contrario de lo que se puede leer. ${ }^{19}$

No se trata de cuestionar (radicalmente) la pertenencia de (una parte de) la Concordia a la literatura polémica, pero ahora bien se sabe que este tipo de obras tiene varias finalidades. ${ }^{20}$ Con esta ponencia, quiero reexaminar las modalidades y los desafíos del discurso antijudaico de Martino de León a la luz de su labor compilatoria, aprovechando los nuevos recursos y herramientas de investigación. Pretendo abordar así el problema interconfesional de la predicación mediterránea con sentido crítico. Me centraré en el uso del Contra Judaeos. ¿Lo utilizó el canónigo leonés en su predicación, para

Viñayo, San Martín de León y su apologética, pp. 95 y 105.

${ }^{14}$ Frugoni, Arnaud de Brescia.

${ }^{15}$ A pesar de algunas críticas: Dahan, Les Intellectuels, pp. 367-368.

${ }^{16}$ Suárez, 'Hospitalidad'; Martín López, 'La hospitalidad'; (escasez de las) actividades pastorales: De Las Heras, 'Généalogie', pp. 346-348.

${ }^{17}$ Viñayo, San Martín de León y su apologética, pp. 64-73.

${ }^{18}$ Drews, The Unknown Neighbour.

${ }^{19}$ Los traductores de la obra isidoriana afirman que 'fue importante para la construcción del armazón ideológico que rodeó la reactivación del antijudaísmo europeo desde finales del siglo XI al siglo XIII', al referirse al estudio de Drews (Castro y Peña, «Introducción», p. 17). Pero él no planteó tal afirmación; al contrario, puso de relieve que el uso del De fide en esa época se reduce casi a la Concordia (sobre la Concordia, el autor depende de los estudios de J. Niclós y A. Viñayo): Drews, The Unknown Neighbour, pp. 313-317. Véase también Fear y Wood ed., Isidore of Seville, p. 186.

${ }^{20}$ Dahan, Les Intellectuels. 
actualizar la lectura del tratado isidoriano con respecto a las necesidades coyunturales ayudando a los canónigos que aspiran a la conversión de los judíos o, a lo menos, que se dedican a la controversia antijudaica - o más bien por respeto a la mayor autoridad doctrinal y espiritual que representa Isidoro sobre la fe en general y la lectio divina en particular - apuntando a propiciar su lectura? El enfoque adoptado permite volver a la cuestión de la relación entre la predicación regular, la realidad secular y la circulación de los modelos y autoridades.

\section{(1) Los sermones de la Concordia y la predicación}

La denominación en los manuscritos originales de cincuenta y cuatro textos de la Concordia como sermones, no determina de manera concluyente su relación con la predicación, entendida como una enseñanza religiosa pronunciada o esperada. ${ }^{21} \mathrm{Al}$ abarcar el término un abanico de propósitos, veamos cuánto verosímil parece que Martino de León escribiera sus textos con el propósito de que él o un hermano suyo los predicara. ${ }^{22}$

En su Vita sancti Martini, Lucas de Tuy (m. c. 1249) describió dos veces al canónigo predicando. ${ }^{23}$ Las dos escenas, que introducen y concluyen prácticamente el relato, ponen de relieve el peso de la predicación en la santidad del canónigo: se hacen eco del ideal de los frailes mendigos que Lucas de Tuy elogió en otra de sus obras, su Johannis heremite visio, en la misma época (años 1230). ${ }^{24}$ Por eso es difícil plantear si se trata de una realidad o si viene del deseo de promover esta nueya forma de vida religiosa.

La documentación no permite determinar muy precisamente las condiciones de la predicación en la colegiata San Isidoro. El Praeceptum, versión de la regla de san Agustín vigente en este establecimiento, no da ninguna orientación relevante. ${ }^{25} \mathrm{Y}$ el libro de las consuetudines desapareció. ${ }^{26}$ Sin embargo, la profesión de los novicios recordó a los canónigos que escucharan las collationes durante la comida, es decir enseñanzas o conferencias espirituales del abad o de otra figura de autoridad. ${ }^{27}$ Tomaban una variedad de formas: homilía, sermón moderno, incluso discusiones informales o tractatus. ${ }^{28} \mathrm{La}$ plasticidad de la mayoría de los sermones de la Concordia se adapta bien al ejercicio, de tal manera que habría posiblemente servido tal forma de predicación comunitaria.

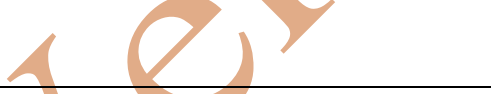

${ }^{21}$ Archivo de San Isidoro de León (= ASIL), MSS XI.1 y XI.2.

Mohrmann, 'Praedicare, Tractare, Sermo', pp. 63-72.

23 Punto de partido sobre la Vita: Henriet, 'Sanctissima patria'. Lucas de Tuy, Vita, col. 11B: 'MiRABANTUR omnes SUPER DOCTRINA EJUS (Mateo 22.33), cum praedicans inter sapientes diserta latinitate verbis positis proponeret verbum Dei'; 21B: 'cum esset prior cum fratribus in capitulo, petiit Dei famulus omnes alios, si qui deerant, convocari, et tam affluenti exhortatione in capitulo verbum Dei proferebat, ut facunda et suavi praedicatione videretur jam consistere in consortio angelorum. Non videbantur esse verba hominis, quia revera Christus loquebatur in servo suo: quaedam inserebat verbis ipsius praedicationis'.

${ }^{24}$ Lerner y Morerod, 'The Vision', p. 205.

${ }^{25}$ ASIL, MS IV, fols 58r-60v y 70r-73v; Regla, ed. Verheijen, pp. 417-437.

${ }^{26}$ Mencionado en los años 1180: ASIL, MS XII, fols 32r y 46r.

27 ASIL, MS XII, fol. 118r: 'Vespere, ad collationem ueniens, uel mane ad capitulum, quod de sacra lectione audierit; memoriter teneat, ut iuxta apostoli uocem non auditor obliuiosus factus sed factor operis: mereatur esse beatus in facto suo'.

${ }^{28}$ Dahan, L'Exégèse, pp. 158-159. 
Al fin y al cabo, hay que estudiar los sermones de Martino de León con esmero para afirmar su relación con la predicación. Antes de hacerlo, repasar algunos puntos puede ser necesario. Un sermón escrito para predicarlo presenta constantes: un discurso, una intención de guiar o influenciar, una relación de autoridad entre el enunciador y el destinatario, el objetivo de instruir y exhortar con fines doctrinales o disciplinarios. Su relación al uso de la palabra, innegable, no se circunscribe fácilmente por lo tanto. No se puede interpretar deícticos o interpelaciones (moneo vos, fratres charissimi, etc.) como referencias a una proclamación. ${ }^{29}$ Además, la relación es de geometría variable. La clasificación de Beverly Kienzle, especialmente pertinente, reconoce sermones del tipo praevius, texto preparando la labor de la predicación; excerptus, que organiza la predicación antes de pronunciarla; literarius, por fin: no se pretende pronunciarlo ni constituir un esquema previo pero ofrecer una exhortación remota, una 'proyección imaginada de un acontecimiento' a través del medium de la lectura. ${ }^{30}$ Hay que añadir las reportationes, notas que toma un auditor a partir de una predicación efectuada. ${ }^{31}$

Entre los denominados sermones de la Concordia, la gama formal es amplia: algunos comentan una capítula (breves citas bíblicas para uso litúrgico) como homilías, otros se parecen más a un sermón moderno, muchos presentan los rasgos de los dos tipos en varias proporciones. No obstante, la mayoría de los sermones es compatible con una $\mathrm{u}$ otra situación de predicación, como lo enseñan los dos ejemplos siguientes.

In Adventu Domini II empieza con una sentencia teológica: Dios, en su gran misericordia, liberó a la humanidad del yugo diabólico tras la Encarnación, anunciada en muchos fragmentos del Antiguo Testamento. De ahí que Martino desarrolló un compendio cristológico: comentó Génesis 18.8-10 para resaltar los errores de los judíos sobre la Encarnación, después describió la segunda Parusía y el Último Juicio - aquí se encuentra dos reinversiones del Contra Juadeos. ${ }^{32}$ El final insta a purificarse de los pecados para preparar el Juicio venidero. El enfoque es temático, el sermón se desarrolla tal y como un examen doctrinal, de manera bastante moderna. ${ }^{33}$ Se relaciona con la liturgia comunitaria ya que comenta entre otras perícopas bíblicas un conjunto de capítulas derivadas de Isaías (2.2-3), que se leen por los oficios de las horas sexta y nona. ${ }^{34} \mathrm{La}$ forma como las finalidades didácticas y exhortativas del sermón se adaptan bien a una predicación prevista o proyectada, una collatio pronunciada por el tiempo de Adviento por ejemplo.

El inicio del Sermo de Natale Domini, al presentar a Pablo y su Epístola a los Hebreos, comenta algunas capítulas de las vísperas de Navidad derivadas de la Carta. ${ }^{35}$

${ }^{29}$ Kienzle ed., The Sermon, pp. 291-295. Además, se nota el uso de la expresión fratres charissimi en tres de las cuatro explanationes.

${ }^{30}$ Kienzle ed., The Sermon, pp. 171-174 (cita: 174).

${ }^{31}$ Bériou, L'avènement, pp. 73-131.

${ }^{32}$ Martino de León, Opera, col. 39A-58D.

${ }^{33}$ Sobre los rasgos de los sermones moderni tales y como se encuentran en el siglo XIII: Bériou, L'avènement, pp. 133-165.

${ }^{34}$ Martino de León, Opera, col. 46C <ET ERIT — DE JERUSALEM>; capítulas: ASIL, MS XII, fol. 6v.

${ }^{35}$ Martino de León, Opera, col. 65A-66A: 'Paulus [...] dignitatem apostolatus meruit, atque plus omnibus laborans, multo latius inter caeteros Verbi gratiam seminavit, atque doctrinam evangelicam sua praedicatione implevit, ad eruditionem totius Ecclesiae sic ait: MulTIFARIE, id est multis locutionibus, MULTISQUE MODIS, multis scilicet qualitatibus, ut certiorem fidem rei tot modis intellectae faceret; OLIM DEUS 
Primero, la lectio es continua, como en una antigua homilía y después, brinda el sentido tipológico del conjunto: el Antiguo Testamento anuncia el nacimiento de Cristo. Con una reinversión del Contra Judaeos, el autor insistió en la incredulidad de la que los judíos son culpables ya que las pruebas exegéticas son obvias. Terminó de manera incentiva, con un Credo sintético.

Como en la mayoría de los otros sermones martinianos, las finalidades son las de la predicación ya que mezclan instrucción y exhortación — que sea o no directa. El canónigo entregó enseñanzas incentivas para formar a sus hermanos en los marcos doctrinales, morales y disciplinares, así como para fortalecer en especial la devoción litúrgica con el saber bíblico correspondiente. En la ignorancia de las reglas concretas sobre la predicación y la lectura en San Isidoro, sin embargo, es difícil determinar la posibilidad de una actuación oral, o precisar la relación con la liturgía. Se pronunciaría In Adventu Domini II en seis horas y De Natale Domini en tres o cuatro horas, según las indicaciones de Jean Leclercq. ${ }^{36}$ Por eso, es probable que Martíno de León haya dedicado la mayoría de sus sermones al medium de la lectura personal — predicación proyectada —, o a pronunciar segmentos de los textos durante los servicios religiosos o las collationes — predicación prevista. Quizás los copistas formalizaron tal división de los sermones en varias partes con los indicadores abstractos o animales que se observan en los márgenes, cada dos o tres columnas manuscritas: los intervalos corresponden a unas dos columnas de la $P L$, es decir, unos veinte minutos de predicación. ${ }^{37}$

Dos sermones que citan el Contra Judaeos no parecen al contrario destinados a la predicación. In Natale Domini II no se acaba con una exhortación. La razón de la ausencia excepcional del Amen final puede ser que el sermón no esté completo, como resultado del corte de los cuatro folios finales ${ }^{38}$. Sobre todo, su forma es muy parecida a la del tractatus, por su extensión (casi 200 folios, 467 columnas $P L$ ) y por su estructura. Se nota claramente el tono didáctico, más centrado en la enseñanza sobre la polémica antijudaica (docere) que en la edificación religiosa a partir de la controversia (praedicare). Los mismos rasgos pueden observarse en In festivitate Sanctae Trinitatis, por sus dimensiones (37 folios,

LOQUENS PAT́RIBUS IN PROPHETIS. [Comentario]. Sequitur: NOVISSIME DIEBUS ISTIS LOCUTUS EST NOBIS IN FILIO, in fine videlicet temporum [continuación del comentario]. Locutus est, inquit, nobis in Filio, qui major est prophetis: QUEM CONSTITUIT HAEREDEM UNIVERSORUM; jam scilicet immutabilem haeredem, [continuación del comentario]. PER QUEM FECIT ET SAECULA, [comentario]. QUI CUM SIT SPLENDOR GLORIAE, secundum divinam essentiam; [continuación del comentario] (Hebreos 1.1-3)'. Correspondencia con ASIL, MS XII, fol. 7v: 'Paulus seruus Ihesu Chrispi uocatus apostolus segregatus in euangelio Dei: quod ante promiserat per prophetas suos in Scripturis Sanctis de filio suo qui factus est ex semine Dauid, secundum carnem» y 8r: 'Multipharie multisque modis olim Deus loquens Patribus in prophetis, nouissime diebus istis locutus est nobis in Filio quem constituit heredem uniuersorum per quem fecit et secula'.

${ }^{36}$ Se pronunciaría en una hora, al menos, un sermón ocupando cuatro a cinco columnas en la edición de la PL: Leclercq, 'Recherches', pp. 199-200.

${ }^{37}$ In Adventu Domini II: MS XI.1, fols 4v columna a (Martino de León, Opera, col. 39A), 5ra $\mathrm{r}^{\mathrm{a}}$ (40D), 5v $\mathrm{v}^{\mathrm{a}}$ (41D), $6 \mathrm{r}^{\mathrm{a}}(43 \mathrm{~B}), 6 \mathrm{v}^{\mathrm{a}}(44 \mathrm{~B}), 7 \mathrm{r}^{\mathrm{b}}(46 \mathrm{C}), 7 \mathrm{v}^{\mathrm{b}}(47 \mathrm{D}), 8 \mathrm{r}^{\mathrm{b}}(49 \mathrm{~B}), 11 \mathrm{r}^{\mathrm{b}}$ (57C) y el sermón acaba en la columna 64D. De Natale Domini: MS XI.1, fol. $15 \mathrm{r}^{\mathrm{a}}(68 \mathrm{~B}), 15 \mathrm{v}^{\mathrm{a}}(69 \mathrm{C}), 16 \mathrm{r}^{\mathrm{a}}(71 \mathrm{~A}), 16 \mathrm{v}^{\mathrm{b}}(72 \mathrm{D}), 17 \mathrm{r}^{\mathrm{b}}(74 \mathrm{~B}), 18 \mathrm{r}^{\mathrm{a}}$ (75D), 18 $\mathrm{v}^{\mathrm{b}}(77 \mathrm{~B}), 19 \mathrm{r}^{\mathrm{b}}(79 \mathrm{~B})$ y el sermón acaba en la columna 82D. No extraña que no todos los sermones de la Concordia presenten esa división: los copistas e iluminadores responsables de la ornamentación marginal policromada no han terminado su trabajo; véase De Las Heras, 'Généalogie', pp. 215-217.

${ }^{38}$ Martino de León, Opera, col. 550A. 
81 columnas) y por su contenido. ${ }^{39}$ Trata de la doctrina trinitaria de manera sistemática, apoyándose considerablemente en el manual escolástico de Pedro Lombardo, los Sententiae in IV libris. Sería difícil fragmentar tal texto en varios oficios o collationes.

En resumen, de los ocho sermones que citan el Contra Judaeos, seis se calibraron para una predicación: In Adventu Domini II, De Natale Domini, In Coena Domini II y III, De Resurrectione Domini III e In Ascensione Domini son de tipo praevius o literarius. En este conjunto desatendido por la historiografía, cabe analizar el trabajo de compilación. Vamos a ver hasta qué punto la reutilización de la obra isidoriana respalda el enfoque antijudaico de la Concordia.

(2) La reutilización del Contra Judaeos, un poderoso respaldo antijudaico en la Concordia

Los desafíos de la obra martiniana no se limitan a lo antijudaico. Ya denunció en otros estudios tal lectura excesiva. ${ }^{40}$ Pero cabe decir que la otra religión de Libro preocupaba considerablemente al autor, más de lo que su prólogo anunciaba: al fin y al cabo, Martino denunció más 'la perfidia de los judíos' que a los 'filósofos', 'paganos' y demás 'heréticos'. ${ }^{41}$ A modo indicativo, sobre treinta y cuatro sermones (se excluye los veinte que tratan expresamente de los santos y de los problemas disciplinares), destacan once por abordar los errores hebraicos, más (los sermones 2, 4, 20, 22, 23, 26, 30) o menos $(3,13,18,34)$; y es el tema del sermón-tratado para la Navidad (4), que abarca casi la cuarta parte de la obra entera.

En la inmensa mayoría de ellos, el autor empleó el Contra Juadeos: consideró casi fundamental su uso para desarrollar un discurso antijudaico. La selección en el primer libro es muy larga, ya que el canónigo empleó cuarenta y tres de sus capítulos para proporcionar materia de predicación a sus hermanos. A continuación, veamos la repartición, tal y como se puede visualizarla, al completar las referencias en la $P L$ con las bases de datos textuales numéricas.

\begin{tabular}{|c|l|c|}
\hline \multirow{2}{*}{$\begin{array}{c}\text { Capítulos del libro primero del } \\
\text { Contra Judaeos y sus temas }\end{array}$} & $\begin{array}{l}\text { Uso en la predicación } \\
\text { martiniana (número en la } \\
P L)\end{array}$ \\
\hline $\begin{array}{c}\text { Naturaleza divina de } \\
\text { Cristo }\end{array}$ & 1 & 2 \\
\cline { 2 - 3 } & 2 & 2 \\
\hline $\begin{array}{c}\text { Misterio de la } \\
\text { Trinidad }\end{array}$ & 4 & \\
\hline Encarnación & 5 & \\
\hline $\begin{array}{c}\text { Nacimiento terrenal } \\
\text { de Jesús de Nazaret, }\end{array}$ & 6 & 2 \\
\cline { 2 - 3 } & 7 & 22 \\
\hline
\end{tabular}

${ }^{39}$ Martino de León, Opera, col. 1269-1350.

${ }^{40}$ De Las Heras, 'L'Apocalypse'; Ead., 'Généalogie'.

${ }^{41}$ Martino de León, Opera, col. 31C-32A.

${ }^{42}$ Distribución temática: Castro y Peña, 'Introducción', p. 32. 


\begin{tabular}{|c|c|c|}
\hline \multirow{12}{*}{$\begin{array}{l}\text { que los judíos no } \\
\text { reconocieron }\end{array}$} & 8 & \\
\hline & 9 & \\
\hline & 10 & \\
\hline & 11 & \\
\hline & 12 & \\
\hline & 13 & \\
\hline & 14 & \\
\hline & 15 & \\
\hline & 16 & \\
\hline & 17 & \\
\hline & 18 & 23 \\
\hline & 19 & 23 \\
\hline \multirow{23}{*}{ Pasión } & 20 & 23 \\
\hline & 21 & 22 \\
\hline & 22 & 23 \\
\hline & 23 & 23 \\
\hline & 24 & 23 \\
\hline & 25 & \\
\hline & 26 & 22,23 \\
\hline & 27 & 23 \\
\hline & 28 & 23 \\
\hline & 29 & 23 \\
\hline & 30 & 23 \\
\hline & 31 & 23 \\
\hline & 320 & 23 \\
\hline & 33 & 23 \\
\hline & $\frac{34}{35}$ & 23 \\
\hline & 36 & 23 \\
\hline & 37 & 23 \\
\hline & 38 & 23 \\
\hline & 39 & 23 \\
\hline & 40 & 23 \\
\hline & 41 & 23 \\
\hline & 42 & 23 \\
\hline & 43 & 23 \\
\hline \multirow{6}{*}{$\begin{array}{c}\text { Muerte de Jesús de } \\
\text { Nazaret }\end{array}$} & 44 & 23 \\
\hline & 45 & 23 \\
\hline & 46 & 23 \\
\hline & 47 & 23 \\
\hline & 48 & 23 \\
\hline & 49 & 23 \\
\hline
\end{tabular}




\begin{tabular}{|c|l|c|}
\hline \multirow{4}{*}{ Resurrección } & 50 & 23 \\
\hline & 51 & 23 \\
\cline { 2 - 3 } & 52 & 23 \\
\cline { 2 - 3 } & 53 & 26 \\
\cline { 2 - 3 } & 54 & \\
\hline Misión apostólica & 55 & \\
\hline \multirow{3}{*}{ Ascensión } & 56 & 30 \\
\cline { 2 - 3 } & 57 & 30 \\
\cline { 2 - 3 } & 58 & \\
\hline \multirow{2}{*}{$\begin{array}{c}\text { El Espíritu Santo } \\
\text { sobre los apóstolos }\end{array}$} & 59 & 2 \\
\cline { 2 - 3 } & 60 & 22 \\
\hline \multirow{2}{*}{$\begin{array}{c}\text { Segunda venida en el } \\
\text { día del Juicio final }\end{array}$} & 61 & 22 \\
\hline Epílogo & 62 & 22 \\
\hline
\end{tabular}

El Contra Judaeos estructura la composición de los sermones 23 y 26. Primero, In Coena Domini III se parece a un abreviado del primer libro del Contra Judaeos sobre la Pasión. Recuerda que, al ocurrir la generación de Cristo en los origines, encarnación, pasión y resurrección fueron prefiguradas en el Antiguo Testamento por los patriarcas y tras las palabras de los profetas. ${ }^{43}$ Martino siguió este principio de lectio tipológica al comentar Génésis 37-48 con las Quaestiones de Isidoro. Demostró que la ascendencia, la familia y las tribulaciones de Joseph prefiguraron las etapas de la vida terrenal de Cristo. ${ }^{44}$ Lamentó la incapacidad de los judíos a verlo y luego, su incredulidad. Insistió sobre la culpabilidad de los últimos con un extracto larguísimo del Contra Judaeos: Dios, previendo la ceguera hebraica, acopió por los profetas signos y anuncios pero no los percibieron ni los creyeron los judíos. ${ }^{45}$ Siguió con el comentario de algunas perícopas proféticas, luego con planteamientos doctrinales sobre la conversión de los judíos por los últimos tiempos, y acabó amonestando a los clérigos sobre los abusos ligados a su condición.

La reutilización del Contra Judaeos es fiel en el sentido de que la mayoría de las variantes parezcan procesar de la tradición textual, pero no es pasiva. Martino amplificó considerablemente el extracto en este sermón, de dos maneras. Por una parte, dentro del extracto, completó las interpretaciones bíblicas con adiciones sacadas de la Glossa ordinaria o de los Moralia in Job de Gregorio El Magno: ahí donde Isidoro citó al profeta Zacarías para poner de relieve el anuncio de la venta de Cristo (Zacarías 11.12), Martino

${ }^{43}$ Martino de León, Opera, col. 865B: 'Deus Pater ante omnia saecula Filium sibi aequalem genuit, per quem visibilia et invisibilia cuncta creavit [...]. Ab initio ergo mundi ejusdem Jesu Christi Filii sui nativitatem, passionem et resurrectionem per figuras innotuit, patriarcharum exemplis praesignavit, per prophetas praedixit, per apostolos vero aperte monstravit'.

${ }^{44}$ Martino de León, Opera, col. 865B-870D <Nonne illum - exaltabitur>’.

${ }^{45}$ Martino de León, Opera, col. 871A-894D <Hinc Jeremias — desisteret>. 
interpoló las glosas correspondientes. ${ }^{46}$ Por otra parte, alargó el extracto del obispo sevillano al comentar Zacarías 13 y Isaías 50-57 con la Glossa ordinaria. Le permite tratar de la consecuencias de la Pasión sobre la historia de los judíos, asuntos que no brinda el Contra Judaeos. Segundo, en De Resurrectione Domini III, Martino organizó la parte sobre la resurrección del cuerpo alrededor de las perícopas bíblicas que Isidoro recomendó sobre el mismo tema (I, LIII). ${ }^{47}$ En primer lugar, las interpretó añadiendo largos extractos de la Glossa sobre los Salmos del Lombardo u otros comentarios, a veces tras haber citado las perícopas anteriores o posteriores. ${ }^{48}$ Después, las comentó y precisó la exposición cristológica por la técnica exegética del 'encadenamiento de versículos', al agregar otros versículos bíblicos llamados en su pluma por un tema común, así que las interpretaciones correspondientes. ${ }^{49}$ Por ejemplo, añadió a las citas isidorianas de Salmo 40.9 y 40.11, la de Salmo 40.12, y las explicó con la Glossa del maestro parisino y con la interpretación del pseudo Remigio de Auxerre (¿a partir de un florilegio?): le llega a tratar de la inmortalidad de Cristo. El canónigo precisó que la última fue confirmada por Dios en él que Cristo vive, como se dice en Romanos 6.10: VIVIT, VIVIT DeO ${ }^{50}$ Esa perícopa le permite a modo de transición citar Job 19.25 sobre el Redentor que vive y, de esa manera, añadir un largo extracto de los Moralia in Job de Gregorio el Magno, más extenso que el comentario del versículo. ${ }^{51}$ Resulta una exposición detallada y controlada sobre la resurrección de Cristo y la esperanza en la de los fieles.

Aunque Martino de León reutilizase aquí poco del Contra Judaeos (corresponde a menos de una columna en la $P L$ ), la selección temática de los salmos que rebuscó en la obra-fuente estructura casi toda la predicación a propósito de la resurrección de Cristo (40 columnas de 47). Que las mismas perícopas se encuentren en el tratado isidoriano y en el sermón martiniano no es coincidencia. Lo prueba claramente la cita del salmo 4: para interpretarlo, el canónigo intercaló en su extracto de la Glossa del Lombardo el único comentario que brindó Isidoro sobre la perícopa. ${ }^{52}$

En este caso, queda muy claro que Martino empleó el tratado isidoriano en un sentido antijudaico: el canónigo judaizó el sentido de las otras fuentes con las cuales comentó los salmos elegidos por Isidoro, como las glosas del Lombardo sobre los salmos 3 y 40. No hay que ver en los que actuaron contra Jesús de Nazareth una pluralidad

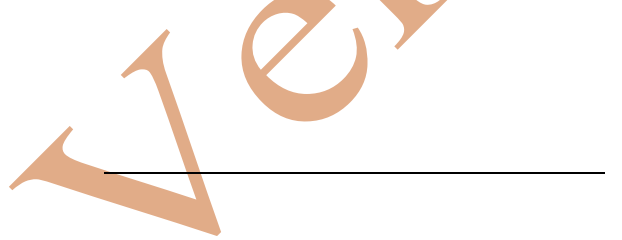

${ }^{47}$ Martino de León, Opera, col. 936D, 937A, 937BC, 952A, 952D, 967C, 967D; Isidoro de Sevilla, Contra Judaeos, col. 492AB.

${ }^{48}$ Martino de León, Opera, col. 952A-953B, 967C-968A, 974D-975C; Pedro Lombardo, In Psalmos, primero 79C-80A y luego 413AB, segundo 89C-90A (sigue con Ps-Remigio de Auxerre, In Psalmos, col. 360C-361 A), por fin 412BC (sigue otra vez con Ps-Remigio de Auxerre, In Psalmos, col. 360BC).

${ }^{49}$ Dahan, L'Exégèse, pp. 138-140.

${ }^{50}$ Martino de León, Opera, col. 953C <Immortalitem — vivit DEO>.

${ }^{51}$ Martino de León, Opera, col. 953D-958D <Et de quo beatus Job - praesumpsit>; Gregorio el Magno, Moralia in Job, ed. Adriaen, XIV, $54: 1.2$ y 58: 1. 3.

${ }^{52}$ Martino de León, Opera, col. 967D <Et hoc - bonorum>; Pedro Lombardo, In Psalmos, col. 89D; Isidoro de Sevilla, Contra Judaeos, col. 492B: 'Singulariter, quia solus ipse sic requievit, ut confestim post mortem resurgeret'. 
indefinida, como lo propuso el maestro parisino, sino a los judíos que castigaron a Cristo y que sufrieron por tanto la dispersión de su pueblo, como lo precisó Martino. ${ }^{53}$

En los dos sermones, el canónigo organizó una arenga antijudaica con el Contra Judeaos, empleándolo tal y como la obra fue elaborada, es decir como una recogida de testimonia bíblicos. Actualizó y amplificó la lectio isidoriana, la interpretación de las citas, con los comentarios producidos en el ambiente escolástico francés que tenían autoridad en la época martiniana: la Glossa ordinaria y la Glossa del Lombardo en primer lugar, así que los comentarios de la alta Edad Media como los Moralia gregorianas. Produjo así un discurso apologético detallado.

En otro sermón, In Coena Domini II, brinda una reutilización similar del Contra Judaeos. Otra vez, aquí el uso es fundamental ya que constituye el protema a partir del cual Martino elaboró un trabajo sofisticado de concordancias bíblicas, que le lleva al tema del error hebraico. ${ }^{54}$

El profeta Jeremías [...] que predijo la muy piadosa Pasión del mismo Redentor, afirmó también eso:

[Contra Judaeos, I, XXI] ${ }^{55}$ El PECADO DE JUdÁ ESTÁ ESCRITO CON PUNZÓN DE HIERRO Y GRABADO CON PUNTA DE DIAMANTE SOBRE TODA LA ANCHURA DE SU CORAZÓN [Jeremías 17.1], lo que concierne convenientemente tanto a Judá como a los judíos, que pecaron así contra Cristo, de tal manera que su pecado no fue escrito con tinta, porque podía borrarse por casualidad, sino grabado con punzón de hierro con punta de diamante; así que no pusiera borrarse debido a la prevaricación de sus corazones, a no ser que hubieran creído in nuestro Señor Jesucristo.

[Comentario de Eusebio Hierónimo, con modificaciones, quizás a través la Glossa ordinaria $]^{56}$ Por tanto, el pecado de Judá es imborrable, tal y como si fuera ESCRITO CON PUNZÓN DE HIERRO Y CON PUNTA DE DIAMANTE, lo que en hebreo se dice samir [...]. Para que lo escrito permanezca para siempre,

53 Martino de León, Opera, col. 952B: 'Judaei saeviunt contra me, sed non dormirem’; Pedro Lombardo, In Psalmos, col. 79C: 'Serviunt illi contra me; sed non dormirem'. Un poco más adelante, son los judíos que 'dispersi sunt' (Martino de León, Opera, col.953A contra Pedro Lombardo, In Psalmos, col. 413A).

Martino de León, Opera, col. 843AC: 'Jeremias propheta [...] de ejusdem Redemptoris piissima passione praedixit, hoc quoque ait: PECCATUM JUDA SCRIPTUM EST STYLO FERREO IN UNGUE ADAMANTINO, EXARATUM SUPER LATITUDINEM CORDIS EORUM: quod sive ad Judam, sive ad Judaeos non incongrue pertinet, qui in Christum peccaverunt, ut non sit peccatum eorum atramento scriptum, quod forte deleri possit, sed stylo ferreo in ungue adamantino exaratum, ita ut deleri non possit praevaricatio cordis eorum, nisi crediderint in Dominum Jesum Christum. Peccatum ergo Juda indelebile est, quasi scriptum stylo ferreo in ungue adamantino, quod Hebraice dicitur samir [...]. [Ut] scriptura in aeternum maneat, secundum illud: SANGUIS EJUS SUPER NOS ET SUPER FILIOS NOSTROS. Alibi etiam hic propheta in persona Christi ait: ATTENDE, DOMINE, AD ME, ET AUDI VOCES ADVERSARIORUM MEORUM. Judaeorum scilicet dicentium: CRUCIFIGE, CRUCIFIGE EUM. In typo Salvatoris Jeremias a Judaeis universa perpessus est [...]. Et imprecatio eorum in aeternum completur. SANGUIS EJUS VIDELICET SUPER NOS, ET SUPER FILIOS NOSTROS'.

55 Isidoro de Sevilla, Contra Judaeos, col. 479A; Contra los judios, trad. por Castro y Peña, p. 84.

${ }^{56}$ Eusebio Hierónimo, In Hieremiam, ed. Reiter, III, 205 : 1. 12-21; Glossa ordinaria, ed. por Rusch, III, fol. $136 \mathrm{r}^{\mathrm{b}}$. 
siguiente eso: SU SANGRE SOBRE NOSOTROS, Y SOBRE NUESTROS HIJOS (Mateo 27.25).

En otro parte, el profeta dice como si fuera Cristo: MIRA POR Mí, SEÑOR, Y OYE LA VOZ DE LOS QUE CONTIENDEN CONMIGO (Jeremías 18-19); [Glossa ordinaria sobre Jeremías] ${ }^{57}$ y como si fuera los judíos, diciendo: ¡CRUCIFÍCALE, CRUCIFÍCALE! (Luc 23.21). Tal el Cristo en el sentido típico, Jeremías sufrió por los judíos, a través del tiempo y del espacio [...]. Y su imprecación [de los judíos] se cumple por la eternidad: es decir SU SANGRE SOBRE NOSOTROS, Y SOBRE NUESTROS HIJOS (Mateo 27.25). [Sigue el comentario de Jeremías 18]

El extracto, una cita interpretada de Jeremías 17.1, pone de relieve el rasgo imborrable del pecado hebraico; Martino lo enriqueció con el comentario de Eusebio Hierónimo; eso le lleva a citar Mateo 27.25, tradicionalmente utilizado en la polémica antijudaica; ${ }^{58}$ por fin, la presencia del versículo evangélico en la Glossa margínal sobre Jeremías 18 le permitió llegar al comentario correspondiente, con el cual desarrolló su discurso antijudaico. ${ }^{59}$ En suma, Martino convocó el Contra Judaeos comò epígrafe, o sea como punto de referencia inicial sobre la inefabilidad del pecado hebraico.

A pesar del importante enfoque antijudaico en algunos sermones de la Concordia, notablemente sostenido por la reutilización del Contra Judaeos, el hecho de que la predicación fuese destinada a judíos es muy sospecho. La polémica directa se concentra en el sermón-tratado In Natale Domini II y es muy escasa en los demás textos. ${ }^{60}$ Además, el uso del Contra Judaeos se caracteriza por su conservadurismo: el canónigo leonés siguió el modelo isidoriano en el sentido de que no incorporó el enfoque lógico y gramatical para demostrar la inanidad de la lectio judía, como lo hizo en el siglo XII Gilbert Crespin, por ejemplo. ${ }^{61}$ Por lo tanto, no resulta una interpretación aventurada el suponer que la predicación fuese más bien destinada a los canónigos de San Isidoro de León, como el resto de la Concordia.

Dada la actualización de la lectio de los testimonia elegidos por Isidoro, y el fortalecimiento de la apología cristiana resultante, Martino de León tal vez pretendiera proporcionar a sus hermanos un material adecuado para que ellos elaborasen una predicación antijudaica. Pero ni siquiera este último punto es probable. El uso del Contra Judaeos siguió más bièn un principio general de la polémica que, como la describió Gilbert Dahan, generalmente es destinada a 'enseñar la superioridad de su fe, no tanto para convencer a su interlocutor comopara tranquilizar a todos los que escuchen y tengan la misma confesión'. ${ }^{62}$ La afirmación parece tanto más relevante cuanto que en este caso, vamos a ver que numerosas reutilizaciones del tratado isidoriano no apuntaron a la lucha contra los judíos, sino a la edificación de los canónigos de San Isidoro.

\footnotetext{
${ }^{57}$ Ibid., fol. 138r $\mathrm{r}^{\mathrm{b}}$.

${ }^{58}$ Dahan, 'L'article Iudei', p. 110.

${ }^{59}$ Martino de León, Opera, col. 843AC <PeCCATUM JUdA — Filios nOSOTROS>.

${ }^{60}$ Rucquoi, 'L'invective'.

${ }^{61}$ Drews, The Unknown Neighbour, p. 314; Abulafia, Christians and Jews, pp. 98-99.

${ }^{62}$ Dahan, La polémique chrétienne, introd.
} 


\section{Edificar a los canónigos}

Martino de León reutilizó también el Contra Judaeos con motivos otros que polémicos. In Adventu Domini II, desarrolla en su primera parte un discurso muy antijudaico, al condenar a los hebreos por el no haber percibido la Encarnación; pero es sólo a lo largo de la segunda parte, donde describe la segunda Parusía, que el autor copió un breve extracto de la obra visigótica, ofreciendo con los capítulos 61 y 62 las anuncias proféticas de la segunda venida de Cristo y del Juicio. ${ }^{63}$ Intercaló extensivos comentarios bíblicos (Glossa, Quaestiones in Genesim y Sententiae de Isidoro), así como exposiciones doctrinales aferentes (Sententiae de Pedro Lombardo) y morales (Moralia in Job) ${ }^{64}$ Martino no respectó el orden de la presentación isidoriana: elaboró su propio discurso a la vez doctrinal y moral sobre el final de los tiempos.

De manera similar, las reutilizaciones en el sermón De Natale Domini sirven para una lectio tipológica con un enfoque cristológico. A propósito del nombre de Cristo, por ejemplo, Martino reforzó la cita y la interpretación isidoriana de Números 13.7 gracias a algunas glosas — de las cuales es muy difícil precisar el origen: ${ }^{65}$

La primera mención del nombre Jesús se encuentra en la figura de Nuestro Señor Jesucristo, anunciada antes: de hecho, aquel hijo de Nun recibió de Moisés el nombre de Jesús. Tras la muerte de Moísés, al convertirse en jefe, el Señor proporcionando y ayudándolo, obtuvo el principado y distribuyó en herencia la tierra de promisión a los hijos de Israel mediante sorteo. ¿Qué significaba el cambio de nombre, si no que, una vez muerto Moisés, es decir, muerta la Ley y siendo inútil el precepto legal, íbamos a tener como futuro jefe al Señor Jesuscristo, él que nos condujera a la tierra de promisión celesta de redención, santificados por medio de las aguas de Jordán.

En el sermón In Ascensione Domini, el autor brindó de nuevo una exposición cristológica, al diseminar las testimonia elegidas por Isidoro a propósito de la ascensión al

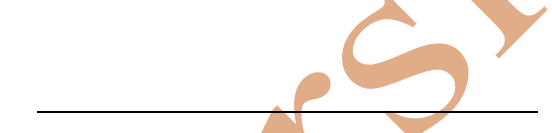

${ }^{63}$ Martino de León, Opera, col. 38C-47C, 47D-59B, 59C-64C.

${ }^{64}$ Extracto en el desorden de Isidoro de Sevilla, Contra Judaeos, col. 496D-500A en Martino de León, Opera, col. 47D-48A <Quod autem de coelis - ET TRADAM EI (Ezequiel 21.27)>; 49A <Iterum dicit: DOMINUS - SUOS CONFORTABITUR (Isaías 42.13-14)>; 49B <Iterum subjungit, dicens: TACUI — ABSORBEBO SIMUL (Isaías 52.14)>; 49BD <Hoc ad secundum — IN REFRIGERIUM (Salmo 65.12)>; 50A <Sequitur: ADVOCABIT - POPULUM SUUM (Salmo 49.4)>; 50B <Iterum dicit: CONGREGATE — SUPER SACRIFICIA (Salmo 49.5)>; 50C <Sequitur: ET ANNUNTIABUNT - qui nascetur>; 51AB <Unde etiam Isaias ait: AUDITAM — angelorum>; 52AC <De cujus judicio Michaeas — orta'; 52C-53A <Haebraeorum — declaravimus>; $53 \mathrm{BC}<$ Huic simile - regnantem> (la parte 55B sq. 'De loco autem judicii' no viene del Contra Judaeos sino de la reutilización de las Sententiae del Lombardo que copió un extracto del tratado isidoriano). Por fin: Martino de León, Opera, col. 58D-59B <Scriptura sacra - designatur>; Gregorio el Magno, Moralia in Job, ed. Adriaen, XXXIV, 7, 1. 2-59.

65 Martino de León, Opera, col. 66C-67A (subrayado: variantes que proceden probablemente de la tradición textual; en negrita: otras variantes): 'Appellatio nominis Jesu prima in figura Domini nostri Jesu Christi invenitur antea praedicta: nam quidam Nave Filius a Moyse cognominatur Jesus [veáse Números 13.17]. Hic enim post obitum Moysi dux effectus, Domino sibi tradente atque jubente, principatum obtinuit, et terram promissae haereditatis filiis Israel sorte divisit. Mutatio nominis quid significabat, nisi quia, defuncto Moyse, id est defuncta lege, et legati praecepto cessante, dux nobis Dominus Jesus Christus erat futurus, nosque ad coelestis repromissionis terram per Jordanis fluenta, [...] sanctificatos perducturus [...]'; Isidoro de Sevilla, Contra Judaeos, col. 463A. 
cielo y de la sentada a la derecha del Padre. ${ }^{66}$ Abandonó la casi totalidad de los comentarios del obispo (cuando existen). Prefirió intercalar otros comentarios, que sean personales o - más numerosos - extractos de la Glossa ordinaria o del Lombardo sobre los salmos, es decir de los dos depósitos de sentidos bíblicos los más autorizados dentro del famoso marco de las escuelas ultra pirenaicas. Observémoslos con la pauta de un empleo del Contra Judaeos: ${ }^{67}$

[Contra Judaeos I, LVI: elección e introducción de una cita bíblica] De ahí que el profeta exhorte a todas las naciones a alabar a Dios, anunciando con esas palabras la ascensión de Cristo: REINOS DE LA TIERRA, CANTAD A DIOS, CElebrad a Dios. Y de nuevo: CElebrad A Dios, Él QUE ASCIENDE HACIA ORIENTE SOBRE EL CONFÍN DE LOS CIELOS (Salmo 67.33). ${ }^{68}$

[Sustitución del comentario del Lombardo al lugar de la interpretación isidoriana] CELEBRAD, lo digo, A DIOS, es decir a Cristo, Él QUE ASCIENDE según su naturaleza humana. De verdad, según su naturaleza divina, es igual al Padre. $[\ldots]^{69}$

[Vuelta al Contra Judaeos: cita bíblica] Et Amós dice: EL SEÑOR HA EDIFICADO EN EL CIELO SU ASCENSO Y ASENTÓ EN LA TIERRA SU PROMESA (AmOs 9.6). ${ }^{70}$

[Al no proponer Isidoro ninguna interpretación, Martino completó con la Glossa ordinaria] Cotidiano, Dios edifica su ascensión al cielo, al traer sus ángeles, que preside, de abajo hacia el cielo y al ascender escoltado por ellos. $^{71}$

[Vuelta al Contra Judaeos, reorganización] De verdad también lo afirma el Señor por medio de Isaías, pone de manifiesto el testimonio sobre la resurrección y ascensión de JesuCristo: AHORA ME LEVANTARÉ UNIDO, DICE EL SEÑOR, AHORA SERÉ ENSALZADO, AHORA SERÉ GLORIFICADO (Isaías 33.10). [Adición martiniana] No sólo se puso de pie, pero resucitó a varios con él. [Contra Judaeos, interpretación isidoriana] Como si dijera abiertamente: AHORA ME LEVANTARÉ de entre los muertos, AHORA SERÉ ENSALZADO en los

${ }^{66}$ Isidoro de Sevilla, Contra Judaeos, col. 494A-495C, cita: Daniel 7.13, que encontramos en Martino de León, Opera, col 1171B; Salmo 18.6: col. 1087D-1088A; Salmo 23.7: col. 1172C-1173A (diseminación); Salmo 17.11: 1143C; Salmo 67.19: 1140C; Salmo 67.33, Amos 9.6, Isaías 33.10, Isaías 53.13, Salmo 109.1, Salmo 46.9: 1144D-1147B (diseminación).

${ }^{67}$ Algunas traducciones proceden de Contra los judíos, trad. por Castro y Peña, pp. 106-107.

${ }^{68}$ Martino de León, Opera, col. 1145CD: 'Unde Propheta hortatur omnes gentes ad laudem Christi, eamdem ascensionem his verbis praenuntians: REGNA TERRAE, CANTATE DEO; PSALLITE DOMINO. Et iterum: PSAllite DEO, QUi ASCENDIT SUPER COELUM COELI AD ORIENTEM'; Isidoro de Sevilla, Contra Judaeos, col. 494D-495A.

69 Martino de León, Opera, col. 1145D-1146A: de 'PsAllite, inquam, DeO, id est Christo, QUI ASCENDIT secundum quod homo est. Nam secundum quod Deus est, Patri aequalis est' hasta 'virtute Verbi'; Pedro Lombardo, In Psalmos, col. 618BC.

${ }^{70}$ Martino de León, Opera, col. 1146A: 'Unde etiam Amos propheta ait: AEDIFICAVIT DominUS IN COElO ASCENSUM SUUM, ET POLLICITATIONEM IN TERRA FIRMAVIT'; Isidoro de Sevilla, Contra Judaeos, col. 495A.

${ }^{71}$ Martino de León, Opera, col. 1146A: 'Quotidie Deus aedificat ascensionem suam in coelo, cum sanctos suos de imis ad coelestia trahit, quibus ipse praesidet, et in eis ascendit'; Glossa ordinaria, ed. por Rusch, III, fol. 270r ${ }^{\mathrm{a}}$, margen. 
cielos, AHORA SERÉ GLORIFICADO en el reino. De ahí Isaías, de nuevo, dice: He AQUÍ QUE MI SIERVO ESTARÁ LLENO DE SABIDURÍA, SERÁ ENSALZADO Y SERÁ COMPLETAMENTE GLORIFICADO (Isaías 52.13). [Adición martiniana] Esta elevación hasta el cielo de JesuCristo, Hijo de Dios y de la Virgen, el profeta David considerándola en el sentido espiritual, y hablando de lo futuro casi como de lo pasado, dice en los Salmos: [Vuelta al Contra Judaeos I, LVII: cita bíblica] DiJo El SEÑOR A MI SEÑOR, SIÉNTATE A MI DIESTRA, HASTA QUE PONGA A TUS ENEMIGOS COMO ESCABEL DE TUS PIES (Salmo 109.1). ${ }^{72}$

[Interpolación de la Glossa del Lombardo] Al explicar primero la natura divina, el profeta dice $\left[\ldots .{ }^{73}\right.$

[Vuelta al Contra Judaeos: interpretación isidoriana sobre Salmo 109.1 y otra cita bíblica] Los judíos se preguntan pues a quién le dijo el Señor SIÉNTATE A MI DIESTRA. Tal vez [...]. Él que es digno de estar en su compañía es digno de tener su misma naturaleza y nombre. [Adición martiniana] El proprio David, profeta, a propósito de todas las naciones de las cuales preveía el reino, afortunadamente instruido con el Espíritu Santo, [Vuelta al Contra Judaeos] decía: El SEÑOR REINARÁ SOBRE TODAS LA NACIONES; DIOS SE SIENTA SOBRE SU SANTO SOLIO (Salmo 46,9). ${ }^{74}$

[Interpolación de la Glossa del Lombardo] Como si decía: Los que desprecian al Cristo humilde, sucumben al menos a su poder. ${ }^{75}$

El canónigo conservó numerosas citas bíblicas escogidas sobre un problema cristológico, dejando de lado la mayoría de las interpretaciones correspondientes: es muy importante este tipo de reutilización del Contra Judaeos, despojada de todo enfoque antijudaico. Así aparece que el autor se sirvió de su fuente como un depósito autorizado y temático de testimonia bíblicas, que trate del error hebraico o no, de la misma manera que utilizó en la Concordia las Sententiae del Lombardo para desarrollar un discurso doctrinal, o las Etimologiae del obispo sevillano para definir literalmente una palabra de la biblia (animal, árbol ....). ${ }^{76}$

${ }^{2}$ Martino de León, Opera, col. 1146AB: 'Nam et illud quod per Isaiam Dominus clamat, testimonium resurrectionis et ascensionis Jesu Christi declarat: NuNC CONSURGAM, DICIT DOMINUS; NUNC EXALTABOR, ET NUNC SUBLIMABOR. Non enim solus surrexit, sed multos secum resuscitavit. Ac si aperte dicat: NUNC EXSURGAM, scilicet a mortuis; NUNC EXALTABOR in coelo, NUNC SUBLIMABOR in regno. Unde iterum Isaias ait: ECCE INTELLIGET SERVUS MEUS; EXALTABITUR, ET SUBLIMIS ERIT VALDE. Quod utique ad ascensionem Christi, et ad gloriam pertinet regni. Hanc in coelo exaltationem Filii Dei et Virginis Jesu Christi David propheta in spiritu intuens, ac de futuro quasi de praeterito loquens, ait in Psalmis: DixIT DominUs DoMINO MEO: SEDE A DEXTRIS MEIS, DONEC PONAM INIMICOS TUOS SCABELLUM PEDUM TUORUM'; Isidoro de Sevilla, Contra Judaeos, col. 495B.

73 Martino de León, Opera, col. 1146B-1147A <Propheta quippe naturam — aeternitate>; Pedro Lombardo, In Psalmos, col. 997C-998C.

${ }^{74}$ Martino de León, Opera, col. 1147AB: 'Inquirant ergo Judaei cui est a Deo Patre dictum, SEDE A DEXTRIS MEIS. [...] Qui sicut consessu suo dignus est, ita natura et nomine dignus est. Ipsum quippe David propheta super omnes gentes regnare praevidebat, cum Spiritu sancto edoctus gratulanter dicebat: REGNABIT DEUS SUPER GENTES; DEUS SEDET SUPER SEDEM SANCTAM SUAM.'; Isidoro de Sevilla, Contra Judaeos, col. 495BC.

${ }^{75}$ Martino de León, Opera, col. 1147BD <Quasi diceret: Qui humilem Christum contemnunt, saltem potestati ejus succumbant. — promissiones'; Pedro Lombardo, In Psalmos, col. 456D-457A.

${ }^{76}$ De las Heras, 'Martin de León (m. 1203) et la culture scolaire ultra-pyrénéenne. Les Sentences de 
De ahí que destaquen en la redacción martiniana dos motivos fundamentales distintos del enfoque antijudaico. Primero, resulta central fortalecer la instrucción exegética de sus auditores o lectores para propiciar su lectio divina, completar la cultura de los hermanos de San Isidoro, más que convencer a los judíos de su error. ${ }^{77}$ El canónigo añadió breves presentaciones sobre la relevancia de la selección de versículos - a pesar de que procediera del Contra Judaeos - e interpoló extractos de las modernas herramientas bíblicas que son las Glossae, para actualizar las interpretaciones. Lo prueba bien una serie de interpolaciones dentro de un extracto estructurante del Contra Judaeos, en el sermón In Coena Domini III. Por ejemplo, el autor asentó la aseveración según la cual el sacrificio de Cristo apuntó a la remisión de los pecados de los fieles y no de los suyos, al desarrollar la lectio de Génesis 49.9 gracias a una precisa compilación exegética.

\begin{tabular}{l} 
In Coena Domini III: \\
pauta del trabajo de compilación(resumen) \\
\hline - Cita del Contra Judaeos I, XLIV \\
La muerte de Cristo fue ya explicada en el Antiguo Testamento: SE ECHÓ A \\
DORMIR COMO UN LEÓN O COMO UN CACHORRO DE LEÓN. ¿QUIÉN LO \\
DESPERTARÁ? (Génesis 49.9). ${ }^{78}$ \\
\hline - Exegesis Génesis 49.9 \\
Adición martiniana de una concordancia exegética: se entiende y la muerte \\
de Cristo, y Génesis 49.9, gracias al versículo precedente que se refiere a la \\
bendición de Judá por su padre el profeta Joseph: TU MANO [él de Juda] EN \\
LA CERVIZ DE TUS ENEMIGOS (Génesis 49.8). ${ }^{79}$ \\
\hline - Exegesis Génesis 49.8-9. \\
Premisa con interpolación de las Etymologiae, a propósito de los \\
patriarcas: La elección del nombre de Judá se relacionó con la confesión. ${ }^{80}$ \\
Interpretación con interpolación de las Quaestiones sobre Génesis $49.8-9$ \\
y adiciones martinianas orientando la lectio ${ }^{81}$ : por eso, se entiende a Judá \\
y el león como figuras de Cristo. \\
Nota: Martino inserta breves adiciones a propósito de la "salvación del \\
mundo" y del "maligno enemigo", el diablo, para poner de relieve el \\
enfoque soteriológico del discurso. ${ }^{82}$
\end{tabular}

Pierre Lombard dans la Concordia'; De Las Heras, 'Généalogie', 477-492..

${ }^{77}$ Martino de León, Opera, col. 1099D: 'Haec ideo, fratres charissimi, ex sanctorum virorum dictis huic lectioni inseruimus, ut facilius intelligere valeat charitas vestra'.

${ }^{78}$ Martino de León, Opera, col. 887D-888A <Quia Dei — SUSCITAVIT EUM>; Isidoro de Sevilla, Contra Judaeos, col. 488B.

${ }^{79}$ Martino de León, Opera, col. 888A < De quo etiam — INIMICUM TUORUM'.

${ }^{80}$ Martino de León, Opera, col. 888A <Judas — actio>; Isidoro de Sevilla, Etymologiae, ed. Lindsay, VII, vii, 10, 1. 19-22.

${ }^{81}$ Martino de León, Opera, col. 888AC <Judam — natus>; Isidoro de Sevilla, Quaestiones, col. 279AC.

${ }^{82}$ Martino de León, Opera, col. 279B: 'id est, ascendens in crucem, captivos populos redemisti. Et quos ille leo contrarius invaserat, tu moriens eripuisti'; Martino de León, Opera, col. 888B: 'id est pro salute mundi crucem ascendisti, et per eam captivos populos redemisti: et quos ille leo contrarius, scilicet malignus hostis, invaserat, tu moriens eripuisti'. 


\begin{tabular}{|l|}
\hline - Excursus didáctico sobre los leones con interpolación de las \\
Etymologiae $^{83}$
\end{tabular}

Aunque Martino necesitase solo un corto extracto de la presentación isidoriana sobre los leones, para realizar el salto hermenéutico hacia la interpretación alegórica de Cristo velando por la salvación de los fieles (los leones, cum dormierint, vigilant oculi), lo insertó todo. Es decir que cuando Martino acometía explicar el Contra Judaeos, no perdía de vista el afán didáctico — el instruir a sus hermanos sobre la Biblia —, menos de igual importancia que el afán apologético.

Otro pasaje del In Coena Domini III señala que el proceso didáctico apunta al enfoque deontológico: el edificar a sus hermanos como canónigos. Dentro de un extracto del Contra Judaeos I, XXIV tratando del Juicio y acabándose con Miqueas 6.1, Martino interpola la Glossa correspondiente hasta Miqueas 6.10, sobre la acción diabólica en la historia de la salvación. ${ }^{85}$ Aunque el fragmento no transmita explicación bíblica inmediatamente necesaria, la adición no es solo didáctica u oportunista. Frente a Contra Judaeos I, XXVI (quitó el XXV), Martino presentó el papel del diablo en la muerte de Cristo gracias a los Moralia in Job: el enemigo no consiguió la pérdida de Cristo en el desierto por sí solo, sino manipulando después a los judíos que se convirtieron en sus auxiliares (satellites) ${ }^{86} \mathrm{El}$ eco con la exegesis sobre Miqueas, con las adiciones precedentes que vimos a propósito de la asociación tipológica Cristo-león también, subraya que la inserción del diablo no es una coincidencia, no procede sólo de la oportunidad de citar a Gregorio el Magno: Martino utilizó su saber exegético para difundir enseñanzas sobre la acción del demonio, diseminándolas en la copia de sus fuentes a lo largo del sermón, el cual acabó con un arengue más general sobre los malos canónigos. El autor los judaizó, poniendo de relieve que ellos siguen el ejemplo de los judíos al ser motivados por las instigaciones diabólicas. ${ }^{87}$ El discurso exegético y polémico sirve al fin y al cabo para la edificación moral y disciplinar.

83 Martino de León, Opera, col. 888C-889A <Cujus genus - interimunt'; Isidoro de Sevilla, Etymologiae, ed. Lindsay, XII, ii, 4: 1. 19 - 6: 1. 4.

84 Martino de León, Opera, col. 889AB <Valde — ILLUD>; Isidoro de Sevilla, Quaestiones, col. 279C-280A.

${ }^{85}$ Martino de León, Opera, col. 874A-875B <AUDITE — THESAURUS INIQUITATIS'; Glossa ordinaria, ed. por Rusch, III, fol. $277 \mathrm{r}^{\mathrm{b}}-277 \mathrm{v}^{\mathrm{a}}$.

${ }^{86}$ Martino de León, Opera, col. 875B-876C <Quia a falsis — auctorem>; sobre la acción diabolica mediatizada, veáse a Gregorio el Magno, Moralia in Job, ed. Adriaen, IX, 28, 1. 2-11 <Quid enim terrae non ualuit>.

${ }^{87}$ Martino de León, Opera, col. 920AB: 'multi peccatum Judae exhorrent, nec tamen cavent. Nam qui hodie in sancta Ecclesia praelatis suis mala pro bonis retribuunt [...]; quid aliud quam perversa traditoris Judae exempla sequuntur? Qui etiam praepositos suos odio habent, eorumque actus, diabolo instigante [...] Judae Iscariotis intra sanctam Ecclesiam locum tenent'. 
Segundo, a Martino le importaba que los destinarios conociesen y entendiesen perfectamente la obra isidoriana, sea en un marco polémico u otro. Es una herramienta de selección bíblica para su trabajo homilético, sobre todo por lo que atañe a la cristología. Al faltar una edición científica del Contra Judaeos con un stemma, es difícil entender el uso exclusivo del primer libro por Martino. Quizás dependa de una tradición manuscrita parcial. Quizás señale no sólo el interés para el afán antijudaico sino también, la desconfianza del canónigo hacia las Sententiae del Lombard sobre el tema por la acusación de nihilismo cristológico. ${ }^{88}$ Por lo que se refiere al asunto del segundo libro isidoriano, eclesiológico, Martino de León prefirió las mismas Sententiae o las obras de Beda, por ejemplo. Más allá del papel de caja de testimonia temáticos, en opinión del canónigo, el Contra Judaeos es una obra fundamental, de la cual el autor intentó brindar un conocimiento controlado. Si bien en los sermones examinados, nunca nombró a Isidoro al copiar un fragmento del Contra Judaeos, al contrario de lo que hizo cuando se trata de las Sententiae o de las Etimologiae, paradójicamente, eso pone de relíeve el índole de autoridad de la obra. Aquí, el nombre del Santo no apunta a acreditar el discurso del canónigo, pero su ausencia señala bien que con el Contra Judaeos, se trata de una obra presuntamente conocida por los destinarios de la Concordia; es una cuestión aquí de profundizar su estudio. Resulta la convicción profunda del canónigo de la importancia fundamental de la obra para la edificación tan exegética que ética de sus hermanos.

El primer como el segundo puntos demuestran que el canónigo se preocupaba menos de la polémica antijudaica que de la edificación exegética y moral de los canónigos, una y otra inseparables.

\section{Conclusión}

Los afanes con los cuales Martino de León tan reutilizó el Contra Judaeos son varios pero la conversión de los judíos, de facto, no es uno de ellos - el caso del tratado-sermón parece un hápax en la Concordia. Las arengas no se redactaron por razones coyunturales. Sin embargo, la predicación antijudaica representa una parte importante de la obra martiniana; gracias al tratado de Isidoro de Sevilla, resulta autorizada y potente. Esa predicación apuntaba a un discurso apologético conforme con los objetivos del santo patrón, es decir que identificaba los errores exegéticos de los hebreos para servir la lectio divina de los cristianos. El canónigo leonés reutilizó el Contra Judaeos como un depósito de testimonia bíblicos muy conveniente por lo que atañe a la cristología, por ser organizado de manera temática. Que trate o no del error hebraico, no es lo más relevante. Amplificándolo, le permitío desarrollar un discurso con fines exegéticos y doctrinales que se encargaba de actualizar. La presencia muy notable del Contra Judaeos en el homiliaro de Martino de León pretendía, al fin y al cabo, instruir a sus hermanos con un modelo que ellos necesitaban dominar: era importante que conocieran la obra por el peso de la autoridad del santo patrón, por la fuerza de su demostración apologética y por la utilidad

${ }^{88}$ Rosemann, Peter Lombard, pp. 131-133 ; Châtillon, 'Latran III'. 
bíblico-temática relevante para escribir otros sermones. De tal manera, Martino facilita la lectio divina en la comunidad de San Isidoro así como la edificación: se trata de negociar una identidad no tan confesional como estatutaria, canónica.

\section{Fuentes y estudios citados}

\section{Manuscritos}

León, Archivo de San Isidoro de León, MS IV.

León, Archivo de San Isidoro de León, MS XI.1 y XI.2.

León, Archivo de San Isidoro de León, MS XII.

\section{Fuentes primarias}

Biblia latina cum glossa ordinaria. Facsimile reprint of the editio princeps, ed. por Adolph Rusch of Strassburg, 4 vols (Turnhout: Brepols, 1992).

Eusebio Hierónimo, In Hieremiam prophetam libri sex, ed. por Sigofredus Reiter, Corpus Scriptorum Ecclesiasticorum Latinorum, 125 (Vienne: Tempsky, 1960).

Gregorio el Magno, Moralia in Job, ed. por Marc Adriaen, Corpus Christianorum Series Latina, 143, 2 vols (Turnhout: Brepols, 2005).

Isidoro de Sevilla, Isidori Hispalensis Episcopi 'Etymologiarum' sive 'Originum' libri XX, ed. por Wallace Martin Lindsay, 2 vols (Oxford: University Press, 1989).

, De fide catholica ex Veteri et Novo Testamento contra Judaeos in Patrologiae cursus completes: series latina, ed. por Jacques-Paul Migne, LXXXIII (Paris: Garnier, 1844-64), col. 449-538.

- Sobre la fe católica contra los judios, trad. por Eva María Castro Caridad y Francisco Peña Fernández (Sevilla: Secretariado de Publicaciones, 2012).

-, Mysticorum expositiones sacramentorum seu Quaestiones in Vetus Testamentum in Patrologiae cursus completes: series latina, ed. por Jacques-Paul Migne, LXXXIII (Paris: Garnier, 1844-64), col. 207-424.

Lucas de Tuy, Vita sancti Martini in Patrologiae cursus completes: series latina, ed. por Jacques-Paul Migne, CCVIII y CCIX (Paris: Garnier, 1844-64), col. 9-24.

Martino de León, Opera omnia in Patrologiae cursus completes: series latina, ed. por Jacques-Paul Migne, CCVIII y CCIX (Paris: Garnier, 1844-64), col. 27-1352 y 9-420.

Pedro Lombardo, In Totum Psalterium Commentarii [Ex Editione Parisiis AD 1541] in Patrologiae cursus completes: series latina, ed. por Jacques-Paul Migne, XCCI (Paris: Garnier, 1844-64), col. 31-1296.

Ps-Remigio de Auxerre, Enarrationum In Psalmos Liber Unus in Patrologiae cursus completes: series latina, ed. por Jacques-Paul Migne, CXXXI (Paris: Garnier, 1844-64), col. 133-844. 
La Regla de san Agustín, ed. por Luc Verheijen, in La règle de saint Augustin, Vol. 1: Tradition manuscrite (Paris: Études augustiniennes, 1967).

\section{Estudios}

Bériou, Nicole, L'Avènement des maîtres de la Parole. La prédication à Paris au XIII ${ }^{e}$ siècle, Études augustiniennes, 31-32, 2 vols. (Paris: Institut d'études augustiniennes, 1998).

Castro Caridad, Eva María, y Peña Fernández, Francisco, 'Introducción', in Isidoro de Sevilla. Sobre la fe católica contra los judíos, Literatura, 121 (Sevilla: Secretariado de Publicaciones, 2012), pp. 13-45.

Châtillon, Jean, 'Latran III et l'enseignement christologique de Pierre Lombard', in Le troisième concile de Latran (1179). Sa place dans l'histoire (Paris: Études augustiniennes, 1982), pp. 75-90.

Dahan, Gilbert, La polémique chrétienne contre le judaïsme au Moyen Âge (Paris: Albin Michel, 1991).

- «L'article Iudei de la Summa Abel de Pierre le Chantre », Revue d'Études Augustiniennes et Patristiques, 27, $\mathrm{n}^{\mathrm{o}}$ 1-2 (1981).

$\longrightarrow$, Les Intellectuels chrétiens et les juifs au Moyen Âge, Patrimoines (Paris: Le Cerf, 2007).

— L'Exégèse chrétienne de la Bible en Occident médiéval: XII -XIV siècle. Patrimoines (Paris: Le Cerf, 1999).

De Las Heras, Amélie, 'Généalogie d'une œuvre à (in)succès. Lectures et écritures de la Veteris ac Novi Testamenti Concordia dans la collégiale de Saint Isidore de León (1148-1240)', (tésis doctoral inédita, E.H.E.S.S., 2013).

— , 'L'Apocalypse chez Martin de León (m. 1203), entre commentaire et sermon. Une lectio divina tournée vers l'action', Mélanges de la Casa de Velázquez. Nouvelle série, venidero.

— Sentences de Pierre Lombard dans la Concordia', Memini. Travaux et documents, 18 (2014).

Díaz y Díaz, Manuel C., 'Isidoro en la Edad Media hispana', in De Isidoro al siglo XI. Ocho estudios sobre la vida literaria peninsular, (Barcelona: El Albir, 1976), pp. 143201 .

Drews, Wolfram. The Unknown Neighbour: The Jew in the Thought of Isidore of Seville, The Medieval Mediterranean, 59 (Leiden: Brill, 2006).

Elfassi, Jacques, 'Les Psaumes dans le De fide catholica contra Iudaeos d'Isidore de Séville: analyse de quelques passages', in Judaïsme et christianisme dans les commentaires patristiques des Psaumes, ed. por Marie-Anne Vannier (Bern: Peter Lang, 2015), pp. 165-183.

Fear, Andrew T., et Jamie P. Wood, Isidore of Seville and His Reception in the Early Middle Ages. Transmitting and Transforming Knowledge, Late Antique and Early Medieval Iberia, 2 (Amsterdam University Press, 2016).

Flórez García, Gonzalo, 'El sacramento de la penitencia en los escritos de Santo Martino', in Santo Martino de León, Cátedra de san Isidoro, 1 (León: Isidoriana, 1987), pp. 655678.

Frugoni, Arsenio. Arnaud de Brescia dans les sources du XII siècle, Histoire, 21 (Paris: Les Belles lettres, 2004). 
Henriet, Patrick, 'Sanctissima patria. Points et thèmes communs aux trois œuvres de Lucas de Tuy', Cahiers de linguistique hispanique médiévale, 24-1 (2001), pp. 249-278.

Kienzle, Beverly Mayne, ed., The sermon, Typologie des sources du Moyen Âge occidental, 81-83 (Turnhout: Brepols, 2000).

Leclercq, Jean, 'Recherches sur les Sermons sur les Cantiques de Saint Bernard. III. Les Sermons sur les Cantiques ont-ils été prononcés?', in Recueil d'études sur Saint Bernard et ses écrits, Storia e letteratura, (Roma: Ed. di storia e letteratura, 1962), pp. 194-212.

Lerner, Robert Earl, y Morerod, Christine, 'The Vision of John, Hermit of the Asturias: Lucas of Tuy, Apostolic Religion, and Eschatological Expectation', Traditio, 61 (2006).

Martín, José Carlos, ed., Sources latines de l'Espagne tardo-antique et médiévale $\left(V^{e}-X I V^{e}\right.$ siècles). Répertoire bibliographique, Documents, études et répertoires, 77 (Paris: CNRS, 2006).

Martín López, María Encarnación, 'La hospitalidad de San Isidoro de León. El Hospital de San Froilán durante los siglos XII al XIV', in El camino de Santiago, la hospitalidad monástica y las peregrinaciones, ed. por Horacio Santiago-Otero, Estudios de historia (Valladolid: Junta de Castilla y León Consejería de cultura y turismo, 1992), pp. 6372.

Mohrmann, Christine, 'Praedicare, Tractare, Sermo. Essai sur la terminologie de la prédication chrétienne', in Études sur le latin des chrétiens, 2: Latin chrétien et médiéval, Storia e letteratura, 87 (Roma: Edizioni di storia e letteratura, 1961), pp. 6372.

Niclós Albarracín, José Vicente, 'San Martín de León y la controversia con los judíos en el siglo XII', in La controversia judeocristiana en España: desde los orígines hasta el siglo XIII, ed. por Carlos del Valle Rodríguez, Controversia, 11 (Madrid: Instituto de filología, 1998), pp. 243-252.

Robles Carcedo, Laureano, 'Fuentes del pensamiento teológico de Santo Martino. Estudio de los cuatro primeros sermones', in Santo Martino de León, Cátedra de san Isidoro, 1 (León: Isidoriana, 1987), pp. 597-622.

Rodríguez, Justiniano, 'Los judíos leoneses en la época martiniana', in Santo Martino de León, Cátedra de san Isidoro, 1 (León: Isidoriana, 1987), pp. 67-86.

Rosemann, Philipp W., Peter Lombard, Great medieval thinkers (Oxford: University Press, 2004).

Rucquoi, Adeline, 'L'invective anti-juive dans l'Espagne chrétienne: le cas de Martin de León', Atalaya, 5 (1994).

Sangirardi, Giuseppe, 'Le modèle dans la transmission des savoirs', Cahiers de recherches médiévales et humanistes, 27 (2014).

Santo Martino de León: ponencias del I Congreso Internacional sobre Santo Martino en el VIII centenario de su obra literaria (1185-1985), Cátedra de san Isidoro, 1 (León: Isidoriana, 1987).

Sapir Abulafia, Anna, Christians and Jews in the Twelfth Century Renaissance, (London: Routledge, 1995).

Scheil, Andrew P., The Footsteps of Israel : Understanding Jews in Anglo-Saxon England, (An Arbor: University of Michigan Press, 2004).

Suárez González, Ana Isabel, 'Hospitalidad y beneficencia en San Isidoro de León: servicios y cargos asistenciales desempeñados por canónigos durante los siglos XII al XVI', Memoria ecclesiae, 10 (1997). 
Toubert, Pierre, y Moret, Pierre, ed., Remploi, citation, plagiat. Conduites et pratiques médiévales ( $X^{e}-X I I^{e}$ siècle), Collection de la Casa de Velázquez, 112 (Madrid: Casa de Velázquez, 2009).

Viñayo González, Antonio, 'San Martín de León, el primer español que cita a Pedro Lombardo', Scriptorium victoriense, 1-1 (1954).

— San Martín de León y su apologética antijudía, (Madrid: CSIC, 1948).

- Santo Martino de León, 1130?-1203: vida, prólogos y epílogos parenéticos de sus tratados, (León: Isidoriana, 2003).

Zimmermann, Michel, ed., Auctor et auctoritas: invention et conformisme dans l'écriture médiévale, Mémoires et documents de l'École des chartes, 59 (Paris: École des chartes, 2001). 